\title{
Preparation and Evaluation of Acetabularia-Modified Carbon Paste Electrode in Anodic Stripping Voltammetry of Copper and Lead Ions
}

\author{
Muhammad Raziq Rahimi Kooh, Jose H. Santos, and Muhammad Khairud Dahri \\ Department of Chemistry, Faculty of Science, Universiti Brunei Darussalam, Tungku Link Road, \\ Bandar Seri Begawan BE1410, Brunei Darussalam
}

Correspondence should be addressed to Muhammad Raziq Rahimi Kooh; chernyuan@hotmail.com

Received 30 May 2013; Revised 16 July 2013; Accepted 17 July 2013

Academic Editor: Hani El-Nezami

Copyright (C) 2013 Muhammad Raziq Rahimi Kooh et al. This is an open access article distributed under the Creative Commons Attribution License, which permits unrestricted use, distribution, and reproduction in any medium, provided the original work is properly cited.

\begin{abstract}
Seaweed is well known about for potential in chelating heavy metals. In this study, carbon paste electrodes were fabricated with siphonous seaweed Acetabularia acetabulum as the modifiers to sense lead (II) and copper (II) by square-wave anodic stripping voltammetry. Various scan rates and deposition potentials were measured to obtain the optimal peak current for $\mathrm{Pb}$ (II) and $\mathrm{Cu}(\mathrm{II})$. Optimum conditions of Acetabularia-CPE for sensing $\mathrm{Pb}$ (II) were at the scan rate of $75 \mathrm{mV} / \mathrm{s}$ and deposition potential of $-800 \mathrm{mV}$, while for $\mathrm{Cu}(\mathrm{II})$ sensing were at $100 \mathrm{mV} / \mathrm{s}$ and $-300 \mathrm{mV}$, respectively. The electrodes were characterized by the duration of accumulation time, preconcentration over a range of standards, supporting electrolyte, and standard solutions of various $\mathrm{pH}$ values. Interference studies were carried out. Both $\mathrm{Zn}(\mathrm{II})$ and $\mathrm{Cu}(\mathrm{II})$ were found to interfere with $\mathrm{Pb}$ (II) sensing, whereas only $\mathrm{Zn}$ (II) causes interference with $\mathrm{Cu}(\mathrm{II})$ sensing. The electrode was found to have good regeneration ability via electrochemical cleaning. Preliminary testing of complex samples such as NPK fertilisers, black soil, and sea salt samples was included.
\end{abstract}

\section{Introduction}

1.1. Background. Brunei Darussalam is a coastal country located at the northern coast of the island of Borneo in Southeast Asia. Although many people who are aware of world's economy and policy know that Brunei is an oil-rich country, some of them are not familiar with its geographical location. Being in Southeast Asia, this country is not only rich in petroleum resources but also possesses high biodiversity in the land and marine environments. Some of these organisms are potential modifiers for biosensor.

The potential of marine aquatic algae is well known for the capability of accumulating high level of heavy metals from the seawater. In seawater, the concentration of heavy metal is very low. At $3.5 \%$ salinity, the typical seawater contains $0.03 \mathrm{ppb}$ lead and 0.9 ppb copper $[1,2]$. According to Campanella et al., brown algae Padina can accumulate 4700 times more copper and 24000 times more lead [3]. Wang et al. reported that the binding site of algae has low affinity for alkaline metal and could trap cationic complexes in the presence of 1000-fold excess of potassium ions [4]. Accumulation of trace metals by algae is usually occurring by biosorption.

Biosorption refers to the removal of heavy metals from an aqueous solution by binding to a nonliving tissue or biomass [5]. Biosorption of metal ions into the cell wall of algae does not require the organism to be alive, and the controlled conditions of metal binding are usually fatal to a living organism [6]. The binding of metal contains a number of passive accumulating processes, which may include adsorption, ion exchange, coordination, complexation, chelation, and microprecipitation [7]. One of the main mechanisms of biosorption is by ion exchange $[8,9]$. Ozer et al. reported that the cell wall of green algae, Cladophora crispata, contained polysaccharide that provided the amino, carboxyl, hydroxyl, phosphoryl, and sulphate groups for metal binding [8]. Cladophora crispata was found to bind $\mathrm{Zn}(\mathrm{II})$ [8] and $\mathrm{Cd}(\mathrm{II})$ [10]. Vasconcelos and Leal mentioned that hydroxyl, sulphate, and carboxyl groups of algal polysaccharides are strong ion exchangers [11]. Vasconcelos and Leal also mentioned that proteins, lipids, and nucleic acid that are present on the cell membrane of 
the macroalgae contain amine, carboxyl, imidazole, thiol, thioester, and the nitrogen and oxygen of peptidic bindings, which can bind metal ions [11]. These qualities of binding trace element make algae an exciting material for fabrication of sensors.

1.2. Siphonous Green Algae. "The siphonous green algae is defined as an assemblage of seaweeds that consist of a single giant cell" [12]. Some families of the siphonous green algae are Bryopsidales, Codiaceae, and Dasycladaceae which include the Codium and Acetabularia species [13].

Cellulose is the main structural polysaccharide that made up the cell wall of higher plant, whereas siphonous green algae, with an exception to Bryopsidales family, utilize other alternatives such as xylan, mannan, or combination of other polysaccharides [14]. The cell wall of Acetabularia species is made up of $\beta$-1, 4-linked mannan as sole crystalline polysaccharide and contains no cellulose [15].

Acetabularia acetabulum (synonymous Acetabularia mediterranea), commonly known as the mermaid's wineglass, was found in abundance along the Brunei coastline, particularly in Jerudong coastal areas [16]. Bispat et al. studied Acetabularia acetabulum collected in Tanjung Batu near Muara Beach in Brunei Darussalam, and determined the concentration of four metals: cadmium, copper, iron, and zinc in the macroalgae. Acetabularia was reported to contain $12.3 \mu \mathrm{gg}^{-1}$ dry weight of cadmium, $100 \mu \mathrm{gg}^{-1}$ copper, 390 $\mu \mathrm{gg}^{-1}$ iron, and $151 \mu \mathrm{gg}^{-1}$ zinc [17]. This finding proved that the Acetabularia acetabulum is capable of accumulating heavy metals.

There is currently no study on the use of Acetabularia species as a modifier for carbon paste electrode (CPE).

1.3. Carbon Paste Electrode (CPE). Carbon paste electrode $(\mathrm{CPE})$ is a sensor for sensing electroactive species and is more commonly used for voltammetric measurements. CPE is popular because of its low cost and the ease of preparation of the sensor.

$\mathrm{CPE}$ is made by mixing the carbonaceous material, liquid binder, and modifiers. The carbonaceous material needs to be of high purity, micrometer in size, and low absorption capability [18]. The most commonly used carbonaceous material for CPE is graphite. Other carbonaceous materials reported to be useful in CPE were the graphene $[19,20]$, glassy carbon microparticles [21], and carbon nanotubes [18]. Liquid binder is required for holding the carbon particles together and needs to be chemically inert, of electroinactivity, low volatility, and minimal solubility, and immiscible with organic solvents. The commonly used binder is mineral oil or paraffin oil. Other common binders are Nujol and Uvasol [18].

CPE is grouped according to the modifier used. The two types of CPE are chemical-modified carbon paste electrode (CMCPE) and carbon paste biosensor (CPB). CMCPE uses either inorganic or organic chemical substances of synthetic origins as modifiers (e.g., polymer, synthetic dyes), whereas CPB material uses substances of natural origins (e.g., enzymes, tissues) [18].
In this study, CPEs were fabricated to analyse copper and lead ions. Some examples of modifiers used in CPE for detecting lead were lichen [22], weed [23], coconut husk [24], and chitosan [25], whereas for copper detection includes algae [6], vermiculite [26], and coal [27].

Copper and lead are very frequently determined using atomic absorption spectrometry (AAS) with flame detection, graphite furnace atomic absorption spectroscopy, inductively coupled plasma atomic emission spectroscopy (ICP-AES), and inductively coupled plasma mass spectrometry (ICPMS) [24]. The disadvantage for both AAS and ICP is the cost of consumables and parts with a limited lifetime and their high operating cost. On the contrary, voltammetric measurements using CPE are relatively inexpensive and have higher sensitivity and selectivity than AAS and ICP-AES.

Copper is a very useful metal which possesses many attractive characteristics for industrial uses and is also considered a micronutrient required by plant and animal. However, high concentration of copper intake can result in toxicity effects in both plant and animal. Symptoms of copper toxicity in plant include chlorosis, poor root growth, and ion leakage through the cell membrane [28], whereas in human, reported toxicity cases included kidney and liver damage, anemia, immune toxicity, and gastrointestinal distress (nausea, abdominal pain, vomiting, and diarrhea) $[29,30]$.

Lead has no nutritional importance in animal diet and can cause severe health hazards if there is an overexposure. Lead usually accumulates in the skeleton and disrupts the enzyme system that is required for the production of haems. Lead also causes kidney tumors and acts as a neurotoxin to the nervous system [31]. Lead can enter the human system through several pathways, for example, the inhalation of dust and polluted air, through the dietary intake of food, water, and medicines, and uses of pottery and porcelain products $[32,33]$.

\section{Aims and Objectives}

The main aim of this study is to develop a low-cost carbon paste electrode (CPE) modified with nucleophilic molecules for the voltammetric determination of copper and lead ions in aqueous samples. The objectives are to fabricate Acetabulariamodified CPE and optimize the parameters so that the same $\mathrm{CPE}$ can detect both copper and lead ions by square-wave anodic stripping voltammetry.

\section{Experimental}

3.1. Instrumental Setup. eDAQ Potentiostat, equipped with e-corder 401 and eDAQ software Echem Version 2.1.5, was used during the evaluation of the electrode. $\mathrm{pH}$ of the standard solutions was adjusted and measured using Thermo Scientific Orion 2 star benchtop $\mathrm{pH}$ meter, and the $\mathrm{pH}$ calibration buffer solutions were obtained from Eurotech. The Acetabularia sample was milled with Perten Instruments Laboratory Mill 3310. The complex samples were analyzed with Shimadzu AA-6701F Atomic Absorption Flame Emission Spectrophotometer.

Three-electrode system was used for the voltammetry, which consisted of a carbon paste electrode with $3 \mathrm{~mm}$ 
internal diameter as the working electrode, a silver-silver chloride reference electrode saturated with $4 \mathrm{M}$ potassium chloride, and a platinum wire as the counter electrode.

3.2. Chemicals and Reagents. The carbon paste was prepared using Sigma-Aldrich graphite powder $(99.99 \%<150$ micron particle size) and Sigma-Aldrich mineral oil. All metal standards (Cd(II), $\mathrm{Co}(\mathrm{II}), \mathrm{Cu}(\mathrm{II}), \mathrm{Ni}(\mathrm{II}), \mathrm{Pb}(\mathrm{II})$, and $\mathrm{Zn}(\mathrm{II})$ ) involved in this study were of analytical grade in nitric acid (Scharlau).

$0.1 \mathrm{M}$ potassium nitrate (Merck, analytical grade) was used as a supporting electrolyte to match the presence of nitrate in the metal standards.

Sodium hydroxide and nitric acid were obtained from Merck and were used for adjusting the $\mathrm{pH}$ of electrolyte and standard solutions of specific $\mathrm{pH}$.

3.3. Preparation of Modifiers. Green macroalgae, Acetabularia acetabulum, was harvested by handpicking from the shallow water lagoon in Tanjung Batu, one kilometer away from Muara Beach, Brunei Darussalam, which was only accessible during low tide. The seaweed Acetabularia was washed and soaked in double distilled water for six hours. The water was replaced with clean distilled water before sonicated for an hour to remove foreign particles such as sand on the surface of the seaweed. Seaweed was oven-dried at $60^{\circ} \mathrm{C}$. Dried seaweed was crushed and milled using Perten Instruments Laboratory Mill 3310 to the smallest particle size of less than $0.5 \mathrm{~mm}$. Milled Acetabularia was then ground using a pestle and mortar to obtain a fine powder.

3.4. Fabrication of CPE. Acetabularia-modified CPE was prepared by mixing $6.4 \mathrm{mg}$ Acetabularia powder (17.4\%), $17.2 \mathrm{mg}$ graphite powder $(45.6 \%)$, and $20 \mu \mathrm{L}$ of mineral oil, which weighed $13.1 \mathrm{mg}$ (35.7\%). Small amount of Acetabularia powder was used because the amount higher than $20 \% \mathrm{w} / \mathrm{w}$ would result in significant expansion of the carbon paste during the analysis, causing the paste to loosen and move out of the electrode during stirring (preconcentration). Smaller amounts of Acetabularia powder (15\% and $16 \%$ ) were also tried and no significant differences were found in the signal.

\subsection{Evaluation of Carbon Paste Electrodes (CPE)}

3.5.1. Cyclic Voltammetry (CV). Cyclic voltammetry (CV) was carried out to determine the potential window of the CPE and to check whether $\mathrm{Pb}$ (II) and $\mathrm{Cu}(\mathrm{II})$ could be analyzed using the modified CPE.

Pure nitrogen was bubbled into the supporting electrolyte for two minutes to purge out other dissolved gases, especially oxygen that may interfere with the CV [34]. The range of CV was set to run in positive initial direction from $-1100 \mathrm{mV}$ to $+1400 \mathrm{mV}$, for one cycle at a scan rate of $100 \mathrm{mV} / \mathrm{s}$.

3.5.2. Anodic Stripping Voltammetry (ASV). The technique used was the square-wave anodic stripping voltammetry (SQ-ASV). Preconcentration was performed by dipping the electrodes in the standards for 1 minute while stirring the solution with a magnetic stirrer. The concentration of standards ranged from $1 \mathrm{ppm}$ to $50 \mathrm{ppm}$.
To explore the effect of accumulation time, the dipping time was extended up to 5 minutes. Accumulation time was studied under four different concentrations of the standard $(1,10,20$, and $50 \mathrm{ppm})$. It was observed that many studies [22, $24,35,36]$ only conducted the measurement of accumulation time at a single concentration of the standard, which may not fully report the potential of the CPE.

Effects of $\mathrm{pH}$ in the supporting electrolyte and in preconcentration standards were also studied. Interference test was conducted by preconcentrating in solution containing interfering ions 50 times higher than the analyte ions. The analysis was carried out in triplicate.

3.5.3. Control Experiment. A blank electrode was fabricated using $15.5 \mathrm{mg}$ of graphite with $8.4 \mathrm{mg}$ of mineral oil. The blank electrode was used to prove that the current peak signal was contributed by the modifier rather than the mineral oil or the graphite.

3.5.4. Electrode Regeneration. After every ASV analysis, electrochemical cleaning was carried out by applying a potential of $+1100 \mathrm{mV}$ for 1 minute and then rinsing with distilled water. The electrolyte was replaced with new clean electrolyte from the stock solution after every analysis to minimize contamination from the previous analysis.

3.6. Preparation of Complex Samples. Four samples (evaporated sea salt, commercial black soil, NPK fertilizer 1, and NPK fertilizer 2) were obtained from local department stores. The granulated fertilizer samples were crushed with a glass rod to improve their solubility. Soil and salt samples were used directly without any treatment. 15-20 g of samples was transferred directly into a conical flask, and $80 \mathrm{~mL}$ of $0.1 \mathrm{M} \mathrm{HNO}_{3}$ was used for the extraction of $\mathrm{Cu}(\mathrm{II})$ and $\mathrm{Pb}$ (II). The samples were subjected to sonication for an hour. The residue was filtered and the filtrate collected in a $100 \mathrm{~mL}$ volumetric flask was topped up to the mark with $0.1 \mathrm{M} \mathrm{HNO}_{3}$. The solution was kept in the refrigerator and analysed within two weeks.

This extraction method for fertilizer and the soil samples may suggest the amount of copper and lead ions extracted within one hour of time using $0.1 \mathrm{MHNO}_{3}$ subjected to ultrasonic treatment. However, these solution extracts could not represent the total amount of copper and lead present in the sample as some insoluble solid remained. The sea salt sample was an exception as all the salt granules were dissolved and thus could represent the total amount of copper and lead ions in the sample.

\section{Result and Discussions}

4.1. Cyclic Voltammetry $(C V)$. The first step of characterization of the electrode is CV. From a cyclic voltammogram, the potential window can be determined, which is a constant region that exhibits the minimal current response [24]. The range of potential within the potential window is useful for the evaluation of electroactive species.

It was observed that the modifier only produced current responses at the extremes of the cyclic voltammogram, 


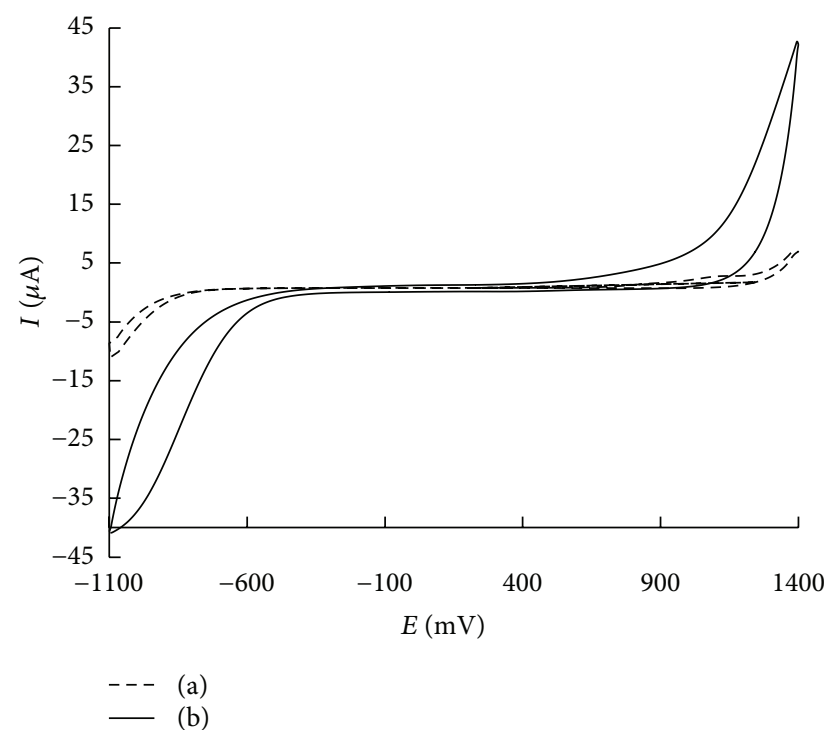

FIgURE 1: One cycle of CV run with a scan rate $100 \mathrm{mV} / \mathrm{s}$ with a potential range from $-1100 \mathrm{mV}$ (initial) to $+1400 \mathrm{mV}$ (final) with positive initial direction for three electrodes: (a) blank electrode; (b) Acetabularia-CPE. The supporting electrolyte is $0.1 \mathrm{M} \mathrm{KNO}_{3}$.

whereas the blank electrode produced no current response from $-1100 \mathrm{mV}$ to $+1200 \mathrm{mV}$ (versus $\mathrm{Ag} / \mathrm{AgCl}$ ) (Figure 1). The potential window of Acetabularia-CPE ranged from $-700 \mathrm{mV}$ to $+900 \mathrm{mV}$.

4.2. Scan Rate and Deposition Potential. All ASV were carried out using SWV. The advantage of SWV over other voltammetric methods is the superb sensitivity and the rejection of background currents, allowing a low detection limit of $10^{-8} \mathrm{M}$. The second advantage is the speed that is coupled with computer control and signal averaging, which allows experiments to be performed repetitively and increases the signal-to-noise ratio [37, 38].

The main aim of optimizing scan rates and deposition potentials was to yield the highest possible peak current and apply it to the rest of the experiment.

The highest peak current obtained at a specific condition is known as the optimum parameter. The optimization of scan rates produced smaller signal differences when compared to the optimization by deposition potentials. The deposition potentials significantly influenced the peak current for both CPEs.

The optimum scan rates for $\mathrm{Pb}$ (II) and $\mathrm{Cu}$ (II) analyses were $75 \mathrm{mV} / \mathrm{s}$ and $100 \mathrm{mV} / \mathrm{s}$, respectively, whereas the optimum deposition potentials were $-800 \mathrm{mV}$ and $-300 \mathrm{mV}$. These optimum scan rates and deposition potentials were applied to the rest of the evaluation of CPE performance (Table 1).

All the peaks produced at the optimum deposition potential for Acetabularia-CPE in both $\mathrm{Pb}$ (II) and $\mathrm{Cu}(\mathrm{II})$ analyses were within the inert potential window as shown by the cyclic voltammetry. This showed that Acetabularia-CPE was suitable for the evaluation of performance with $\mathrm{Pb}(\mathrm{II})$ and $\mathrm{Cu}(\mathrm{II})$.
TABLE 1: Tabular summary showing the average peak currents obtained for various scan rates and deposition potentials for Acetabularia-CPE.

\begin{tabular}{|c|c|c|}
\hline \multirow{2}{*}{$\begin{array}{l}\text { Scan rate } \\
(\mathrm{mV} / \mathrm{s})\end{array}$} & \multicolumn{2}{|c|}{$\begin{array}{l}\text { Average peak current }(\mu \mathrm{A}) \\
\text { of various scan rates }(n=3)\end{array}$} \\
\hline & $\mathrm{Pb}(\mathrm{II})$ & $\mathrm{Cu}(\mathrm{II})$ \\
\hline 50 & $19.80 \pm 0.61$ & $17.86 \pm 0.88$ \\
\hline 75 & ${ }^{*} 21.52 \pm 1.21$ & $17.10 \pm 0.59$ \\
\hline 100 & $18.83 \pm 0.74$ & ${ }^{*} 19.54 \pm 0.45$ \\
\hline $\begin{array}{l}\text { Deposition potential } \\
(\mathrm{mV})\end{array}$ & \multicolumn{2}{|c|}{$\begin{array}{l}\text { Average peak current }(\mu \mathrm{A}) \text { of } \\
\text { various deposition potentials } \\
(n=3)\end{array}$} \\
\hline-1100 & $13.25 \pm 0.45$ & - \\
\hline-1000 & $13.70 \pm 0.26$ & - \\
\hline-900 & $16.82 \pm 0.03$ & - \\
\hline-800 & ${ }^{*} 17.24 \pm 0.19$ & $7.24 \pm 0.83$ \\
\hline-700 & $9.11 \pm 0.67$ & $8.31 \pm 0.33$ \\
\hline-600 & $4.47 \pm 0.53$ & $9.52 \pm 0.61$ \\
\hline-500 & - & $12.88 \pm 0.82$ \\
\hline-400 & - & $19.54 \pm 0.81$ \\
\hline-300 & - & ${ }^{*} 21.58 \pm 1.16$ \\
\hline-200 & - & $10.99 \pm 0.50$ \\
\hline
\end{tabular}

${ }^{*}$ Representing optimum signal.

4.3. Effect of the Concentration of Standard Solution. Acetabularia-CPE was preconcentrated in various concentrations of standard. The concentrations ranged from $0.1 \mathrm{ppm}$ to $50 \mathrm{ppm}$ at accumulation time of one minute. ASV was carried out under optimum scan rate and deposition potential.

$\mathrm{Pb}(\mathrm{II})$ analysis displayed a linear increase ranging from $0.4 \mathrm{ppm}$ to $5 \mathrm{ppm}$, whereas for $\mathrm{Cu}(\mathrm{II})$ analysis ranged from $0.4 \mathrm{ppm}$ to $10 \mathrm{ppm}$ (Figures 2 and 3 ). Beyond the linear region, the graph gradually curved and then became constant. The constant region of the graph is a nature of preconcentration process and is expected to occur because the binding sites present on the electrode surface become saturated [6].

A linear range of both electrodes can be extended by reducing the accumulation time and by not stirring the solution [6]. However, these modifications can reduce the peak current and undesirably increase the detection limit.

4.4. Effect of Accumulation Time. The duration of dipping the modified CPE in a particular concentration of solution has a major effect on the amplitude of the peak current. The peak height increases with the duration of accumulation time, until reaching a saturation point where most of the binding sites on the surface of CPE are occupied.

Acetabularia-CPE generated higher peak current for $\mathrm{Pb}$ (II) than for $\mathrm{Cu}$ (II) under the same applied conditions. The CPE generated a linear increase in the peak current for both $\mathrm{Pb}(\mathrm{II})$ and $\mathrm{Cu}(\mathrm{II})$ at concentrations $1 \mathrm{ppm}$ and $10 \mathrm{ppm}$ and saturation did not occur (Figures 4 and 5). 20 ppm Pb(II) generated peak current that reached saturation at 4 minutes of accumulation, whereas $20 \mathrm{ppm} \mathrm{Cu}$ (II) reached saturation after 3 minutes. $50 \mathrm{ppm} \mathrm{Pb}$ (II) standard displayed an increase 


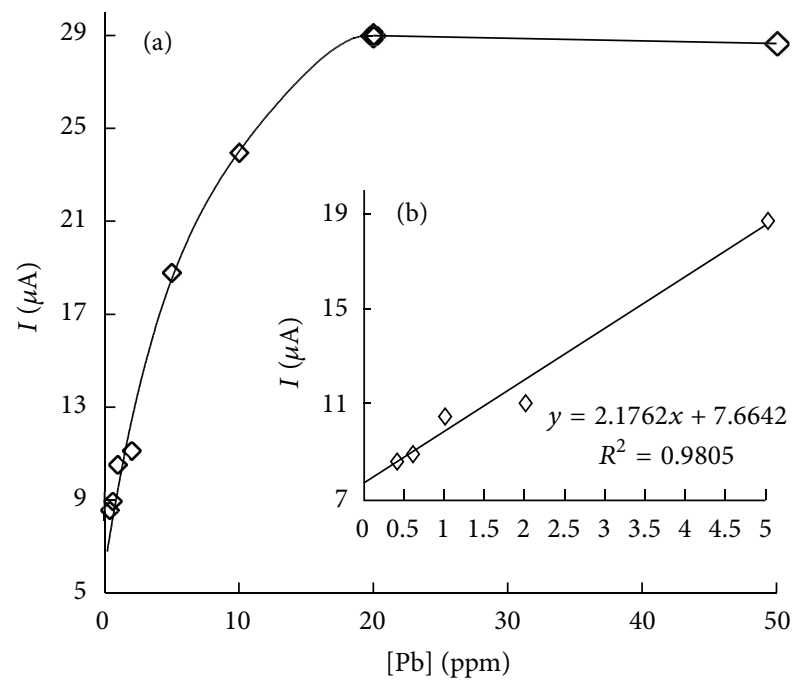

Figure 2: Effect of various preconcentration $\mathrm{Pb}$ (II) standards for the Acetabularia-CPE showing the (a) full range from $0.4 \mathrm{ppm}$ to $50 \mathrm{ppm}$ and (b) linear increase from $0.4 \mathrm{ppm}$ to $5 \mathrm{ppm}$, under the conditions of one minute accumulation, followed by a deposition potential of $-800 \mathrm{mV}$ and a scan rate of $75 \mathrm{mV} / \mathrm{s}$ in $0.1 \mathrm{M} \mathrm{KNO}_{3}$ electrolyte.

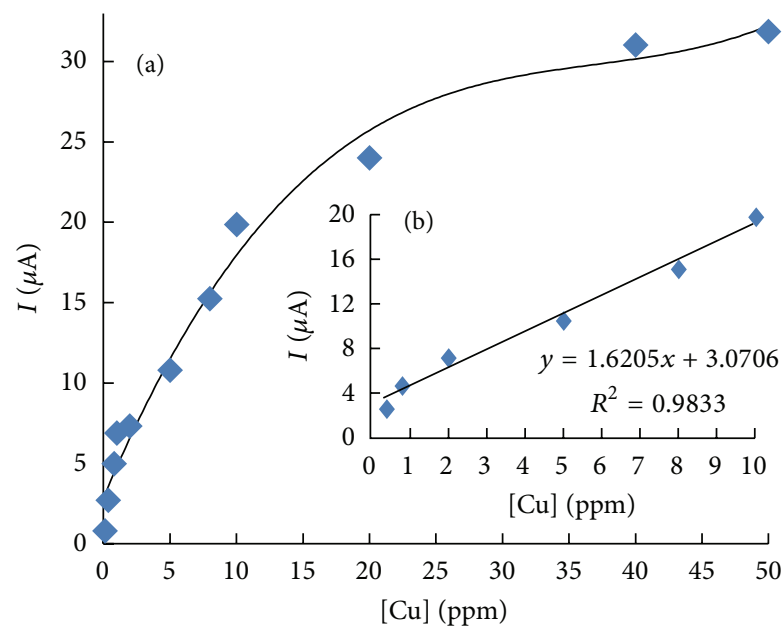

FIGURE 3: Effect of various preconcentration $\mathrm{Cu}(\mathrm{II})$ standards for the Acetabularia-CPE showing the (a) full range from $0.1 \mathrm{ppm}$ to $50 \mathrm{ppm}$ and (b) linear range from $0.4 \mathrm{ppm}$ to $10 \mathrm{ppm}$. The CPE was accumulated for 1 minute followed by a deposition potential of $-300 \mathrm{mV}$ and a scan rate of $100 \mathrm{mV} / \mathrm{s}$ in $0.1 \mathrm{M} \mathrm{KNO}_{3}$ electrolyte.

of peak current from 1 to 4 minutes of accumulation and showed a sign of saturation after the 4 minutes of accumulation, whereas $50 \mathrm{ppm} \mathrm{Cu}$ (II) displayed saturation within one minute.

Similar optimized conditions of $\mathrm{Pb}$ (II) and $\mathrm{Cu}(\mathrm{II})$, used in Acetabularia-CPE, were applied to a blank electrode (CPE with no modifier). The blank electrode served as a control experiment and to show that the majority of the signals were caused by the modifiers. Five-minute accumulation of the blank electrode with ASV carried out at optimum deposition potential and scan rate resulted in no observable

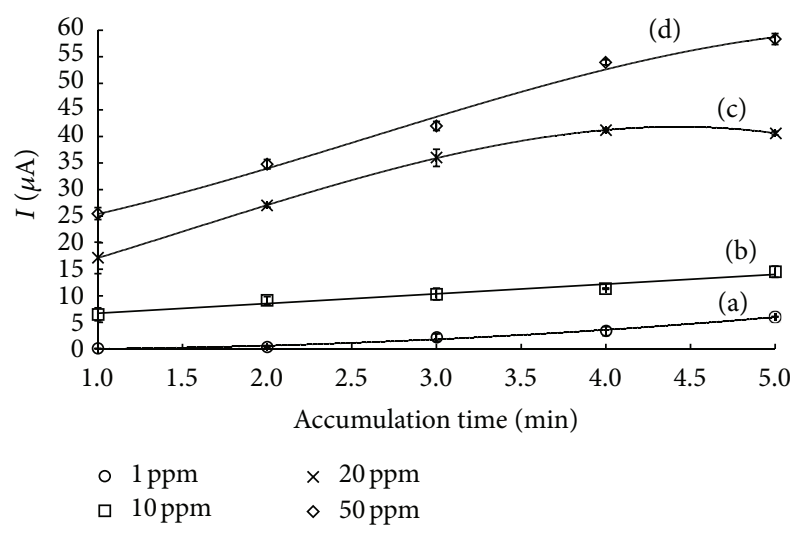

Figure 4: The effects of accumulation time (1 to 5 minutes) for the Acetabularia-CPE for $\mathrm{Pb}$ (II) standard with concentrations of (a) 1, (b) 10, (c) 20, and (d) $50 \mathrm{ppm}$. The applied conditions were deposition potential of $-800 \mathrm{mV}$ and scan rate of $75 \mathrm{mV} / \mathrm{s}$ in $0.1 \mathrm{M} \mathrm{KNO}_{3}$ electrolyte.

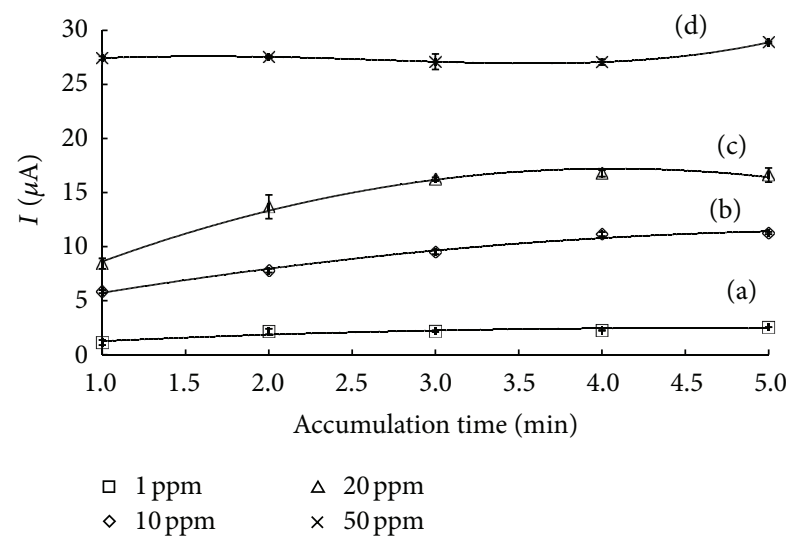

Figure 5: The effects of accumulation time (1 to 5 minutes) for the Acetabularia-CPE in $\mathrm{Cu}(\mathrm{II})$ standard with concentrations of (a) 1, (b) 10, (c) 20, and (d) $50 \mathrm{ppm}$. The applied conditions were deposition potential of $-300 \mathrm{mV}$ and scan rate of $100 \mathrm{mV} / \mathrm{s}$ in $0.1 \mathrm{M} \mathrm{KNO}_{3}$ electrolyte.

peak in $50 \mathrm{ppm} \mathrm{Pb}(\mathrm{II})$ and a peak current of $0.0095 \mu \mathrm{A}$ in the $50 \mathrm{ppm} \mathrm{Cu}(\mathrm{II})$, whereas Acetabularia-CPE produced average peak currents of $58.34 \mu \mathrm{A}$, and $28.89 \mu \mathrm{A}$ respectively, under similar conditions (Figures 4 and 5). This showed that peak current that was generated by the blank electrode was negligible compared with peak current generated by the modified CPE. It was concluded that the graphite and mineral oil did not contribute significantly to any of the peak currents that were generated within 5 minutes of accumulation time.

4.5. Effects of $\mathrm{pH}$ in Preconcentration Standards. $\mathrm{pH}$ is one of the most important characterizations of CPE, and it can greatly influence the peak currents generated by the CPE. All solutions contained fixed concentration of standard at 9.1 ppm. The $\mathrm{pH}$ values of unmodified $\mathrm{Pb}(\mathrm{II})$ and $\mathrm{Cu}(\mathrm{II})$ standards were 2.2 and 2.7 , respectively.

$\mathrm{Cu}(\mathrm{II})$ and $\mathrm{Pb}$ (II) can form insoluble hydroxide compounds when hydroxide ions are introduced. However, there 


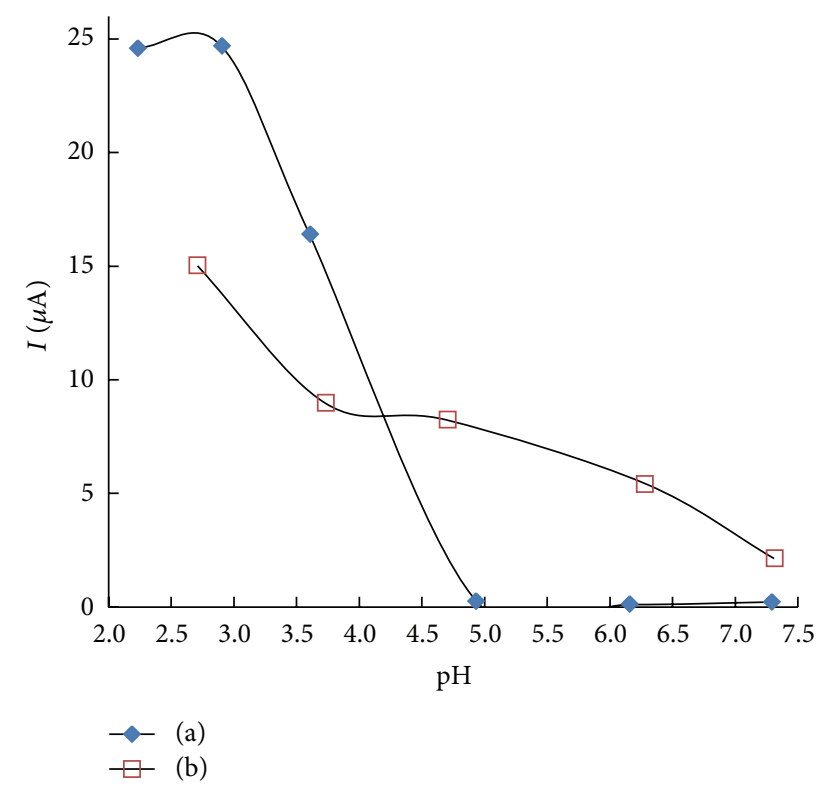

Figure 6: The effect of (a) $\mathrm{Pb}(\mathrm{II})$ and (b) $\mathrm{Cu}(\mathrm{II})$ preconcentration standards of various $\mathrm{pH}$ values for Acetabularia-CPE. The conditions used were one minute of accumulation followed by applying optimum deposition potential and optimum scan rate in $0.1 \mathrm{M} \mathrm{KNO}_{3}$ electrolyte.

was no visible precipitation observed in any of the standard solutions, and this may be due to the low concentration of standard used and low $\mathrm{pH}$ of the preconcentration solutions.

The blank electrode exhibited negligible signal to all preconcentration standards, therefore, confirming that $\mathrm{pH}$ did not help improve binding of analyte ions to the graphite and mineral oil.

The optimum $\mathrm{pH}$ of Acetabularia-CPE in $\mathrm{Pb}(\mathrm{II})$ preconcentration solution was 2.9 (Figure 6). $\mathrm{pH}$ lower than 2.9 showed little difference in the peak current. $\mathrm{pH}$ higher than 2.9 produced a gradual decrease in the $\mathrm{Pb}$ (II) peak current, and at the $\mathrm{pH}$ of 4.9 , the peak current decreased to zero. The optimum $\mathrm{pH}$ of $\mathrm{Cu}(\mathrm{II})$ preconcentrating standard for Acetabularia-CPE is 2.7. The $\mathrm{pH}$ lower than 2.7 showed a gradual decrease in the peak current.

The binding of metal ions to binding sites on the modifiers, especially the algal cell wall, occurs via an ionexchange process [6]. Reduction of peak current as the $\mathrm{pH}$ became more basic was probably due to the formation of lead hydroxide and copper hydroxide, which depleted the cations existence as free ions, and thus less free cations were available at the binding sites of the modifier of CPE.

When the $\mathrm{pH}$ is low enough, the cations need to compete with protons for negatively charged binding sites of modifier [6], and therefore very low $\mathrm{pH}$ can also result in the decrease of peak signal.

4.6. Effects of Supporting Electrolyte of Various $p H$ Values. As different supporting electrolytes were used, the effects may include the differences in the height of the peak currents under similar conditions and may alter the peak potential. In this study, only one electrolyte was used, which was the potassium nitrate.

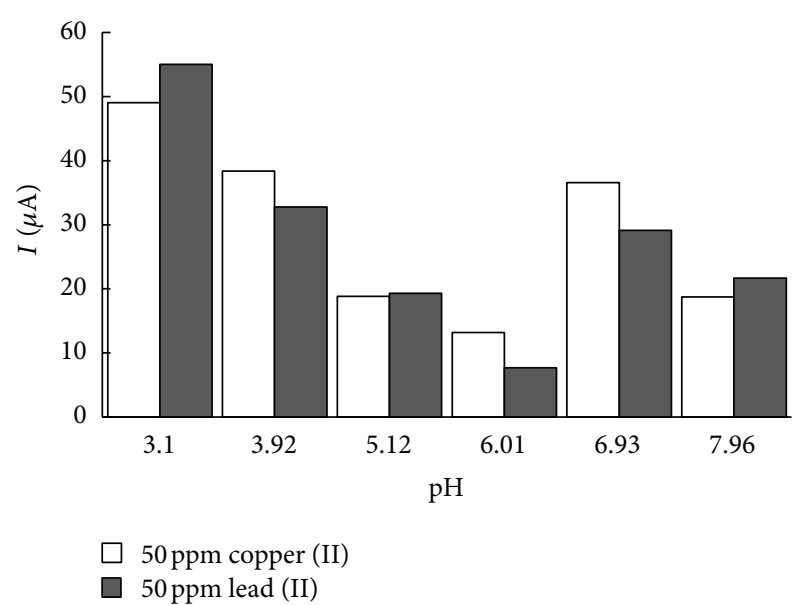

Figure 7: $\mathrm{Pb}$ (II) and $\mathrm{Cu}(\mathrm{II})$ analyses in electrolyte of various $\mathrm{pH}$ values using Acetabularia-CPE. $\mathrm{Cu}$ (II) analysis was carried out with 1 minute of deposition potential of $-300 \mathrm{mV}$ and scan rate of $100 \mathrm{mV} / \mathrm{s}$, whereas lead (II) was carried out with 1 minute deposition potential of $-800 \mathrm{mV}$ and scan rate of $75 \mathrm{mV} / \mathrm{s}$.

$\mathrm{pH}$ of $0.1 \mathrm{M} \mathrm{KNO}_{3}$ was approximately 6.0. The $\mathrm{pH}$ of the $\mathrm{KNO}_{3}$ electrolyte was altered by using $\mathrm{HNO}_{3}$ and $\mathrm{NaOH} . \mathrm{pH}$ below 3.1 was not used just in the case of potential fire hazard as nitrate is an oxidizing agent.

Acetabularia-CPE in both $\mathrm{Pb}(\mathrm{II})$ and $\mathrm{Cu}(\mathrm{II})$ analyses displayed optimum electrolyte $\mathrm{pH}$ at 3.1.

For Acetabularia-CPE, all of the modified $\mathrm{pH}$ electrolytes resulted in a higher peak current than the unmodified supporting electrolyte (Figure 7). The peak current generated by Acetabularia-CPE at pH 3.1 was $55.03 \mu \mathrm{A}$; meanwhile, the unmodified electrolyte ( $\mathrm{pH}$ 6.01) generated a peak current of $7.68 \mu \mathrm{A}$. The Acetabularia-CPE also generated a similar trend in the $\mathrm{Cu}(\mathrm{II})$ analysis, where at $\mathrm{pH} 3.1$ produced a peak current of $49.06 \mu \mathrm{A}$, while at $\mathrm{pH} 6.01$ produced a peak current of $13.30 \mu \mathrm{A}$.

The order of the peak current height for $\mathrm{Pb}(\mathrm{II})$ analysis was $\mathrm{pH} 3.10>3.92>6.93>7.96>5.12>6.01$, whereas for $\mathrm{Cu}(\mathrm{II})$ analysis was $\mathrm{pH} 3.10>3.92>6.93>5.12>7.96>6.01$.

In anodic stripping voltammetry (ASV), the deposition potential (reduction process) dissociated the cations from the binding sites of modifier and diffused to the surface layer from the bulk of the electrode while metal being deposited on the surface is immediately available for the electrochemical oxidation reaction [26]. It could be explained that the optimum $\mathrm{pH}$ may promote the dissociation of cations from the binding sites of the modifier and maintain the cation at the surface layer of the electrode without leaching into the electrolyte. As a result, the cations are available for oxidation during stripping analysis.

4.7. Interference Studies. Interference studies are usually undertaken to establish the selectivity of an analytical method for a particular analyte. For example, an interfering ion can prevent the primary analyte from being effectively accumulated at the electrode surface under certain conditions [26]. There is also a possibility that an interfering ion may produce 
a peak overlapping with the primary analyte peak as observed by Švancara et al. [39] in the analysis of silver ion using CPE.

In this study, we classified changes of peak current of less than $20 \%$ as "weakly" interfered, between $20 \%$ to $30 \%$ change as "moderately" interfered, and any changes higher than $30 \%$ as severely interfered.

$10 \mathrm{ppm}$ standard was chosen because the peak current was large enough to be measured without reaching the point of saturation. Larger peak means a higher signal which can reduce the magnitude of errors. If the concentration used was too low, peak current may be too small and human errors may lead to greater inaccuracy.

The $\mathrm{Pb}(\mathrm{II})$ interference mixtures did not result in any deviation from the $\mathrm{Pb}(\mathrm{II})$ peak potential. It was observed that the Acetabularia-CPE in $\mathrm{Pb}(\mathrm{II})$ standard mixed with 50 -fold $\mathrm{Cu}(\mathrm{II})$ and $\mathrm{Zn}(\mathrm{II})$ interfering ions resulted in a peak current reduction of $74.5 \%$ and $36.2 \%$, respectively (Table 2 ). These observations showed that only $\mathrm{Cu}(\mathrm{II})$ and $\mathrm{Zn}(\mathrm{II})$ resulted in significant reduction of the peak currents generated by $10 \mathrm{ppm} \mathrm{Pb}(\mathrm{II})$ standard. It was concluded that the $\mathrm{Cu}(\mathrm{II})$ and $\mathrm{Zn}$ (II) severely interfered with the $\mathrm{Pb}$ (II) for binding sites on Acetabularia-CPE. Co(II) weakly interfered with $\mathrm{Pb}(\mathrm{II})$ causing a $12.4 \%$ reduction of signal. The rest of the interfering ions did not produce significant changes $(\leq 10 \%)$ as compared with a peak current generated by $10 \mathrm{ppm} \mathrm{Pb}$ (II) and therefore was labelled as very weakly interfered at 50 -fold in concentration.

In $\mathrm{Cu}$ (II) interference analysis, most of the interfering ions weakly interfered with $\mathrm{Cu}(\mathrm{II})$, with an exception of $\mathrm{Zn}$ (II), which caused $23 \%$ reduction in the peak current.

There was no shift of the peak potential for all of the $\mathrm{Pb}$ (II) and $\mathrm{Cu}(\mathrm{II})$ peak currents, including those that were severely interfered. Blank electrode in the interference studies did not show any significant changes to the peak signal.

4.8. Complex Samples. This section of the experiment was a preliminary study of complex samples with AcetabulariaCPE. Interference studies showed that performance of the CPE was reliable when analyzing weakly interfered solution that contained fewer metals; however, the same performance may not be achieved for complex samples.

AAS is the conventional method to measure $\mathrm{Pb}$ (II) and $\mathrm{Cu}(\mathrm{II})$. AAS data is reliable and served as reference data for comparison purposes. Acetabularia-CPE in $\mathrm{Pb}(\mathrm{II})$ analysis of the soil and both NPK fertilizer samples did not reveal any peak (Table 3 ). The absence of $\mathrm{Pb}$ (II) peak may be due to the presence of $\mathrm{Cu}(\mathrm{II})$ or other unknown cations which can compete with $\mathrm{Pb}$ (II) for binding sites. Acetabularia-CPE overestimated the concentration of $\mathrm{Pb}$ (II) in sea salt sample. Determination of $\mathrm{Cu}(\mathrm{II})$ in NPK fertilizer 1 and sea salt by Acetabularia-CPE was close to the value suggested by AAS.

There were uncertainties in the values suggested by Acetabularia-CPE with complex solutions. Acetabularia-CPE may not have worked well with complex samples at current stage because complex samples contain many cations and anions. The presence of other cations (not included in the interference studies) may potentially compete with $\mathrm{Pb}(\mathrm{II})$ and $\mathrm{Cu}$ (II) for the binding sites. The combined effects of many weak and moderate interferences acting together can also produce a large increase or decrease of the peak current. Various anions such as chloride, sulphate, and phosphate present in complex samples and their effects were unknown and not included within the scope of this study.

4.9. Surface Regeneration via Electrochemical Cleaning. One of the main features of a $\mathrm{CPE}$ is the ability of a single electrode to be reused repeatedly. It was observed that electrochemical cleaning through application of fixed potential at $+1100 \mathrm{mV}$ for 60 seconds can remove the analyte that accumulated from the previous experiment to a negligible level. However, when the analyses were done with longer accumulation times or when relatively concentrated solutions were used, residual peaks appear attributable to remaining analytes that were not removed during electrochemical cleaning. For these instances, additional rounds of electrochemical cleaning were performed until the unwanted peaks were no longer observed. Alternatively, incubating the $\mathrm{CPE}$ in $0.1 \mathrm{M} \mathrm{KNO}_{3}$ for 30 minutes can effectively reduce the unwanted peak to a negligible level. Residual peaks after electrochemical cleaning were rarely encountered when analyses were done at lower concentrations or with shorter accumulation times.

It is concluded that electrochemical cleaning is effective for Acetabularia-CPE. A single electrode was observed to still function after approximately 500 runs. These runs were performed within a span of one month and involved analyses of target analyte in standard solutions and samples as well as electrode regeneration using electrochemical cleaning. Ageing effects on electrodes were not observed within the short duration of one month.

\section{Conclusions}

Macroalgal Acetabularia is a good modifier for $\mathrm{CPE}$ in $\mathrm{Pb}(\mathrm{II})$ and $\mathrm{Cu}(\mathrm{II})$ sensing. By finding the optimum parameter, the same modifier can be used for studying different metals other than $\mathrm{Pb}(\mathrm{II})$ and $\mathrm{Cu}(\mathrm{II})$. The optimum scan rate for both $\mathrm{Pb}$ (II) and $\mathrm{Cu}$ (II) was $75 \mathrm{mV} / \mathrm{s}$ and $100 \mathrm{mV} / \mathrm{s}$, respectively, whereas the optimum deposition potentials were $-800 \mathrm{mV}$ and $-300 \mathrm{mV}$. Applying the optimum scan rate and deposition potential produced a higher peak current for successive characterisation.

Longer accumulation time produced a higher peak current, however, with the risk of reaching saturation. A concentration of $10 \mathrm{ppm}$ standard produced sufficient peak signals for the interference studies and the $\mathrm{pH}$ analyses without reaching saturation.

$\mathrm{pH}$ is the most important condition as it directly affected the signal strength. Specific optimum $\mathrm{pH}$ of preconcentration solution usually at the acidic level successfully amplified the peak current of Acetabularia-CPE. pH-modified potassium nitrate supporting electrolyte successfully amplified peak current of Acetabularia-CPE at low $\mathrm{pH}$. Interference studies showed that $\mathrm{Cu}(\mathrm{II})$ and $\mathrm{Zn}$ (II) competed and severely interfered in the activity of $\mathrm{Pb}(\mathrm{II})$ ions for the binding sites on active surface of Acetabularia-CPE. Zn(II) moderately interfered with activity of $\mathrm{Cu}(\mathrm{II})$.

A blank electrode was used to prove that the nonactive ingredients of the carbon paste electrode such as mineral oil 
TABLE 2: Comparison of peak current generated by the standards versus interfering ions.

\begin{tabular}{|c|c|c|c|}
\hline \multicolumn{4}{|c|}{ Changes of peak current in percentage (\%) } \\
\hline & Reagents & $\mathrm{Pb}(\mathrm{II})$ & $\mathrm{Cu}(\mathrm{II})$ \\
\hline \multirow{7}{*}{ Interference to standard ratio of $50: 1$} & $\mathrm{~K}(\mathrm{I})$ & 10.3 & 13.7 \\
\hline & $\mathrm{Cd}(\mathrm{II})$ & 5.9 & 9.3 \\
\hline & $\mathrm{Co}(\mathrm{II})$ & 12.4 & 1.6 \\
\hline & $\mathrm{Cu}(\mathrm{II})$ & 74.5 & $\mathrm{n} / \mathrm{a}$ \\
\hline & $\mathrm{Ni}(\mathrm{II})$ & 4.2 & 15.6 \\
\hline & $\mathrm{Pb}(\mathrm{II})$ & $\mathrm{n} / \mathrm{a}$ & 15.4 \\
\hline & $\mathrm{Zn}(\mathrm{II})$ & 36.2 & 23.1 \\
\hline
\end{tabular}

Format of table assembled according to [39].

TABLE 3: Summary of concentrations of complex samples as suggested by various analytical methods.

\begin{tabular}{|c|c|c|c|c|}
\hline \multirow{3}{*}{ Samples } & \multicolumn{4}{|c|}{ Concentration of heavy metal detected in complex samples $(\mathrm{ppm})(n=2)$} \\
\hline & \multicolumn{2}{|c|}{ AAS } & \multicolumn{2}{|c|}{ Acetabularia-CPE } \\
\hline & $\mathrm{Pb}(\mathrm{II})$ & $\mathrm{Cu}(\mathrm{II})$ & $\mathrm{Pb}(\mathrm{II})$ & $\mathrm{Cu}(\mathrm{II})$ \\
\hline Black soil & $0.24 \pm 0.03$ & $0.18 \pm 0.01$ & $<0.20$ & $1.53 \pm 0.11$ \\
\hline NPK fertilizer 1 & $0.27 \pm 0.05$ & $1.00 \pm 0.05$ & $<0.20$ & $1.35 \pm 0.02$ \\
\hline NPK fertilizer 2 & $0.24 \pm 0.03$ & $0.34 \pm 0.00$ & $<0.20$ & $1.51 \pm 0.12$ \\
\hline Evaporated sea salt & $0.17 \pm 0.01$ & $0.32 \pm 0.00$ & $1.36 \pm 0.10$ & $0.49 \pm 0.06$ \\
\hline
\end{tabular}

and graphite did not contribute significantly to any part of the evaluation procedure.

Acetabularia-CPE was also found to possess good regeneration ability where electrochemical cleaning effectively removed the analyte ions.

\section{References}

[1] A. K. De, Environmental Chemistry, Wiley Eastern, New Delhi, India, 1987.

[2] E. D. Goldberg, "The oceans as a chemical system," in The Composition of Sea-Water Comparative and Descriptive Oceanography, M. N. Hill, Ed., John Wiley and Sons, New York, NY, USA, 1963.

[3] L. Campanella, M. E. Conti, F. Cubadda, and C. Sucapane, "Trace metals in seagrass, algae and molluscs from an uncontaminated area in the Mediterranean," Environmental Pollution, vol. 111, no. 1, pp. 117-126, 2001.

[4] J. Wang, T. Martinez, and D. Darnall, "Electrocatalysis at algae modified electrodes," Journal of Electroanalytical Chemistry, vol. 259, no. 1-2, pp. 295-300, 1989.

[5] T. A. Davis, B. Volesky, and A. Mucci, "A review of the biochemistry of heavy metal biosorption by brown algae," Water Research, vol. 37, no. 18, pp. 4311-4330, 2003.

[6] J. Gardea-Torresdey, D. Darnall, and J. Wang, "Bioaccumulation and measurement of copper at an alga-modified carbon paste electrode," Analytical Chemistry, vol. 60, no. 1, pp. 72-76, 1988.

[7] G. Dönmez, Z. Aksu, A. Öztürk, and T. Kutsal, "A comparative study on heavy metal biosorption characteristics of some algae," Process Biochemistry, vol. 34, no. 9, pp. 885-892, 1999.

[8] D. Ozer, A. Ozer, and G. Dursun, "Investigation of zinc(II) adsorption on Cladophora crispata in a two-staged reactor," Journal of Chemical Technology \& Biotechnology, vol. 75, no. 5, pp. 410-416, 2000.
[9] K. Chojnacka, "Using biosorption to enrich the biomass of seaweeds from the Baltic Sea with microelements to produce mineral feed supplement for livestock," Biochemical Engineering Journal, vol. 39, no. 2, pp. 246-257, 2008.

[10] A. Özer, D. Özer, G. Dursun, and S. Bulak, "Cadmium(II) adsorption on Cladophora crispata in batch stirred reactors in series," Waste Management, vol. 19, no. 3, pp. 233-240, 1999.

[11] M. T. D. Vasconcelos and M. F. C. Leal, "Seasonal variability in the kinetics of $\mathrm{Cu}, \mathrm{Pb}, \mathrm{Cd}$ and $\mathrm{Hg}$ accumulation by macroalgae," Marine Chemistry, vol. 74, no. 1, pp. 65-85, 2001.

[12] H. Verbruggen, M. Ashworth, S. T. LoDuca et al., "A multilocus time-calibrated phylogeny of the siphonous green algae," Molecular Phylogenetics and Evolution, vol. 50, no. 3, pp. 642653, 2009.

[13] P. S. Vroom and C. M. Smith, "The challenge of siphonous green algae," American Scientist, vol. 89, no. 6, pp. 523-531, 2001.

[14] E. L. McCandless, "Polysaccharides of the Seaweeds", in The Biology of Seaweeds, C. S. Lobban and M. J. Wynne, Eds., chapter 16, University of California Press, Berkeley, Calif, USA, 1981.

[15] E. Frei and R. D. Preston, "Non-cellulosic structural polysaccharides in algal cell walls. III. Mannan in siphoneous green algae," Proceedings of the Royal Society of London B, vol. 169, no. 1015, pp. 127-145, 1968.

[16] A. T. White and M. W. R. N. De Silva, "Coastal resources: beaches," in The Coastal Environmental Profile of Brunei Darussalam: Resource Assessment and Management Issues, T. E. Chua, L. M. Chou, and M. S. M. Sadorra, Eds., ICLARM Technical Reports 18, Fisheries Department, Ministry of Development, Brunei Darussalam for Living Aquatic Resources Management, Manila, Phillipines, 1st edition, 1987.

[17] A. S. Bispat, K. R. Fernando, and H. H. Mohd, "Biomonitoring and Biosorption studies on two seaweed species from Brunei Darussalam," Scientia Bruneiana, vol. 7, pp. 21-34, 2006.

[18] I. Švancara, K. Vytřas, K. Kalcher, A. Walcarius, and J. Wang, "Carbon paste electrodes in facts, numbers, and notes: a review 
on the occasion of the 50-years jubilee of carbon paste in electrochemistry and electroanalysis," Electroanalysis, vol. 21, no. 1, pp. 7-28, 2009.

[19] F. Li, J. Li, Y. Feng, L. Yang, and Z. Du, "Electrochemical behavior of graphene doped carbon paste electrode and its application for sensitive determination of ascorbic acid," Sensors and Actuators B, vol. 157, no. 1, pp. 110-114, 2011.

[20] X. Huang, Z. Zeng, Z. Fan, J. Liu, and H. Zhang, "Graphenebased electrodes," Advanced Materials, vol. 24, no. 45, pp. 59796004, 2012.

[21] J. Wang, U. Kirgöz, J. Mo, J. Lu, A. Kawde, and A. Muck, “Glassy carbon paste electrodes," Electrochemistry Communications, vol. 3, no. 4, pp. 203-208, 2001.

[22] H. Yao and G. J. Ramelow, "Biomass-modified carbon paste electrodes for monitoring dissolved metal ions," Talanta, vol. 45, no. 6, pp. 1139-1146, 1998 .

[23] W. Ouangpipat, T. Lelasattarathkul, C. Dongduen, and S. Liawruangrath, "Bioaccumulation and determination of lead using treated-Pennisetum-modified carbon paste electrode," Talanta, vol. 61, no. 4, pp. 455-464, 2003.

[24] D. S. Rajawat, S. Srivastava, and S. P. Satsangee, "Electro chemical determination of $\mathrm{Pb}$ (II) ions by carbon paste electrode modified with coconut powder," in Chemistry of Phytopotentials: Health, Energy and Environmental Perspectives, L. D. Khemani, M. M. Srivastava, and S. Srivastava, Eds., pp. 293-297, Springer, Berlin, Germany, 2012.

[25] R. Y. A. Hassan, I. H. I. Habib, and H. N. A. Hassan, "Voltammetric determination of lead(II) in medical lotion and biological samples using chitosan-carbon paste electrode," International Journal of Electrochemical Science, vol. 3, pp. 935945, 2008.

[26] B. Ogorevc, X. Cai, and I. Grabec, "Determination of traces of copper by anodic stripping voltammetry after its preconcentration via an ion-exchange route at carbon paste electrodes modified with vermiculite," Analytica Chimica Acta, vol. 305, no. 1-3, pp. 176-182, 1995.

[27] Z. Navrátilová, "Coal as a new carbon paste electrode modifier with sorption properties," Electroanalysis, vol. 21, no. 15, pp. 1758-1762, 2009.

[28] W. Ke, Z. Xiong, S. Chen, and J. Chen, "Effects of copper and mineral nutrition on growth, copper accumulation and mineral element uptake in two Rumex japonicus populations from a copper mine and an uncontaminated field sites," Environmental and Experimental Botany, vol. 59, no. 1, pp. 59-67, 2007.

[29] J. K. Fawell, E. Ohanian, M. Giddings et al., Copper in DrinkingWater: Background Document for Development of WHO Guidelines for Drinking-Water Quality, World Health Organisation, Geneva, Switzerland, 3rd edition, 2004.

[30] A. Dorsey, L. Ingerman, and S. Swarts, Toxicological Profile for Copper, Agency for Toxic Substances and Disease Registry, United States Department of Health and Human Services, Atlanta, Georgia.

[31] J. K. Fawell, "Chapter 3: chemical aspects," in Guidelines for Drinking-Water Quality, Volume 1: Recommendations, M. Sheffer, Ed., WHO, Geneva, Switzerland, 1993.

[32] A. Furman and M. Laleli, "Semi-occupational exposure to lead: a case study of child and adolescent street vendors in Istanbul," Environmental Research, vol. 83, no. 1, pp. 41-45, 2000.

[33] W. Liu, Q. Zhou, Y. Zhang, and S. Wei, "Lead accumulation in different Chinese cabbage cultivars and screening for pollutionsafe cultivars," Journal of Environmental Management, vol. 91, no. 3, pp. 781-788, 2010.
[34] J. Wang, Analytical Electrochemistry, John Wiley \& Sons, Hoboken, NJ, USA, 3rd edition, 2006.

[35] S. G. Ward and J. H. Santos, "Fabrication and characterization of polygalacturonic acid-modified carbon paste electrode for electrochemical detection of lead," Scientia Bruneiana, vol. 9, pp. 55-64, 2008.

[36] S. K. Alpat, S. Alpat, B. Kutlu, O. Ozbayrak, and H. B. Buyukisik, "Development of biosorption-based algal biosensor for $\mathrm{Cu}$ (II) using Tetraselmis chuii," Sensors and Actuators B, vol. 128, no. 1, pp. 273-278, 2007.

[37] P. Duckworth, Echem User's Guide \& Using Chart \& Scope Software for Electrochemistry Version 1. 5, ADInstruments, New South Wales, Australia, 1999.

[38] S. P. Kounaves, “Chapter 37: voltammetric techniques," in Handbook of Instrumental Techniques for Analytical Chemistry, F. Settle, Ed., pp. 709-725, Prentice Hall, New York, NY, USA, 1997.

[39] I. Švancara, K. Kalcher, W. Diewald, and K. Vytřas, "Voltammetric determination of silver at ultratrace levels using a carbon paste electrode with improved surface characteristics," Electroanalysis, vol. 8, no. 4, pp. 336-342, 1996. 

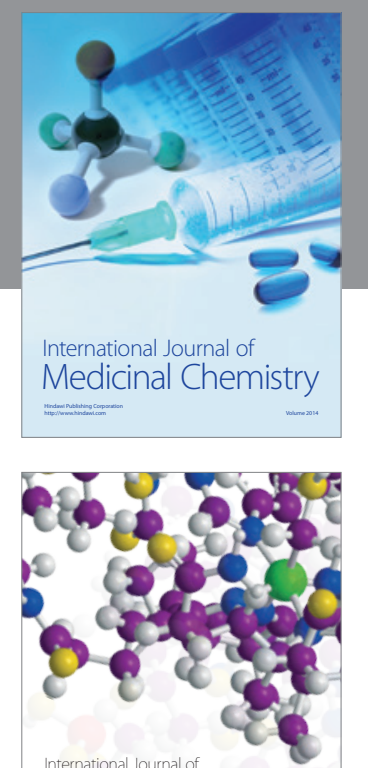

\section{Carbohydrate} Chemistry

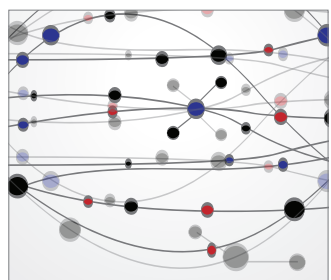

The Scientific World Journal
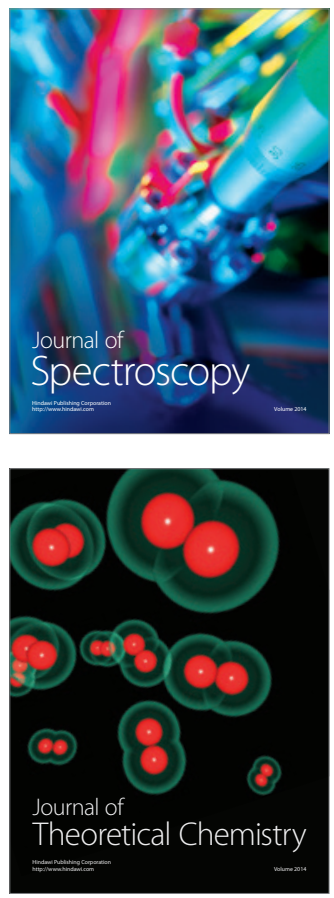
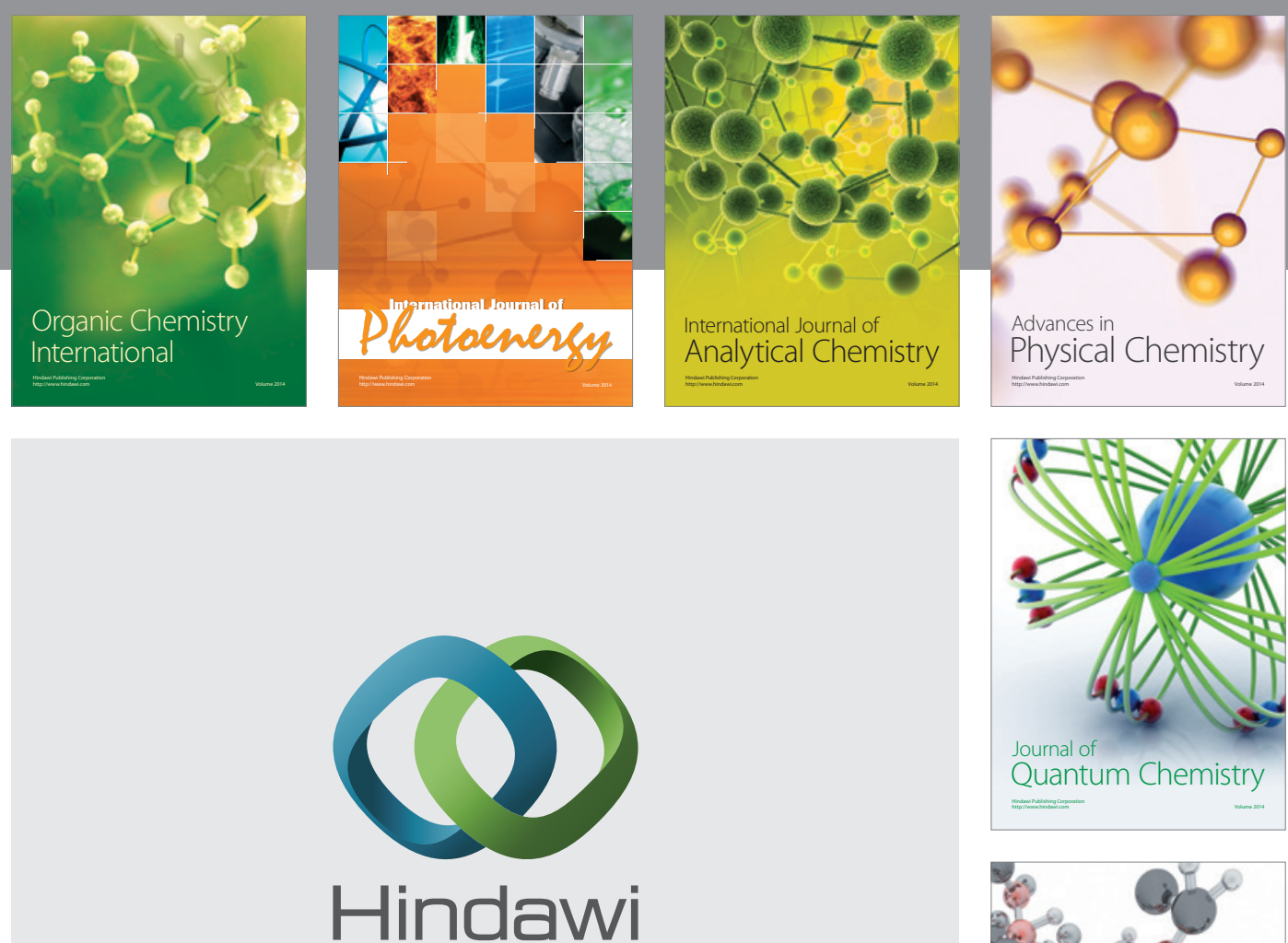

Submit your manuscripts at

http://www.hindawi.com

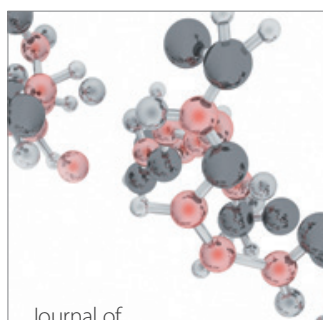

Analytical Methods

in Chemistry

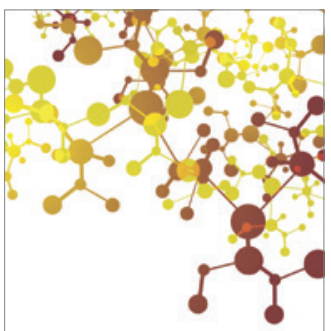

Journal of

Applied Chemistry

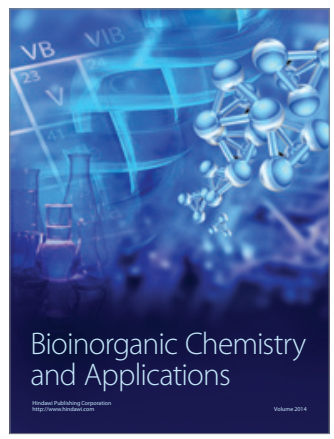

Inorganic Chemistry
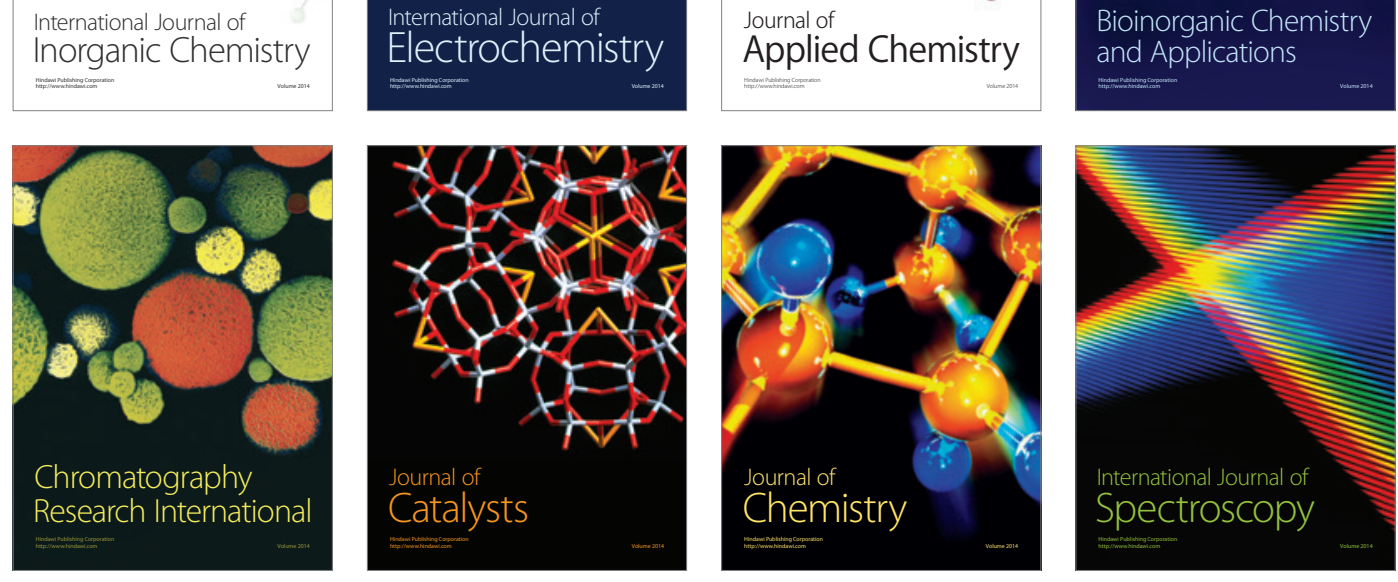